\title{
Bone Resorption in Ameloblastoma and Its Underlying Mechanism
}

\author{
Jackson $^{1}$, Johni Halim ${ }^{1}$, Rezky Anggraeni ${ }^{1}$, Ferry Sandra ${ }^{2 *}$ \\ ${ }^{1}$ Postgraduate Program in Dentistry, Faculty of Dentistry, Universitas Trisakti, Jakarta, Indonesia \\ ${ }^{2}$ Department of Biochemistry and Molecular Biology, Division of Oral Biology, Faculty of Dentistry, Universitas Trisakti, \\ Jakarta, Indonesia
}

\begin{abstract}
Ameloblastoma, a tumor located in the jaw, grows slowly but locally invasive. Ameloblastoma expands in the jaw based on a mechanism resorbing the surrounding bone. To date, the bone resorption mechanisms of ameloblastoma are associated with the expression of receptor activator of nuclear factor (NF)-KB (RANK) ligand (RANKL), matrix metalloproteinases (MMPs), and tumor necrosis factor (TNF)-a. RANKL plays an important role in generating osteoclastogenesis. MMPs degrade the extracellular matrix. TNF- $a$ can induce the formation of osteoclast and modulate the MMPs. In this review the bone resorption mechanism of ameloblastoma as well its signaling pathway will be disclosed.
\end{abstract}

Keywords: Ameloblastoma, RANKL, MMPs, TNF-a.

\section{INTRODUCTION}

One of the most common benign epithelial odontogenic tumors of the jaw is ameloblastoma. Ameloblastoma has the characteristics of slow growth and locally invasive. The peak incidence of ameloblastoma is in the third and fourth decades of life, but ameloblastoma can occur at all ages, equal in gender distribution. In Caucasians, most ameloblastomas occur in the molar-ramus region, with over $50 \%$ prevalence. Most ameloblastomas occur in the mandibular symphysis in the Asian Indian and Nigerian population (Petrovic, et al., 2018). Ameloblastoma usually occurs in a unilateral form (95\%). Overall, ameloblastomas arise mostly in the mandible (80-93\%) (Singh, et al., 2015). In Indonesia, multicystic follicular ameloblastoma was the most common type (57\%), followed by unicystic (25\%) and unspecified multicystic (18\%) (Ruslin, et al., 2018). In Southeast Myanmar and Lower Northern Thailand, ameloblastoma was shown multilocular radiolucency in $70 \%$ cases and unilocular radiolucency in 30\% cases. Unicystic ameloblastoma (20\%), conventional solid/multicystic ameloblastoma (70\%), and desmoplastic ameloblastoma (10\%) were diagnosed in Lower Northern Thailand, Southeast Myanmar, and Thailand regions. The most common histologic pattern was the plexiform type (57.2\%), followed by the follicular type (23.8\%) (Intapa, 2017).

A 40-year epidemiologic study in Iran showed the most frequent location of the tumor was the mandibles (93.2\%) (Saghravanian, et al., 2016). Ameloblastoma is mainly located in the third molar region; $20 \%$ of ameloblastoma arises in the

Submitted: January 12, 2021

Revised: February 23, 2021

Accepted: February 25, 2021

*Corresponding author: ferry@trisakti.ac.id 
maxilla, particularly in the posterior region. Desmoplastic ameloblastoma, a rare subtype ( $2 \%$ of all ameloblastomas), arises most frequently in the premolar and anterior regions of the mandible and the maxilla (Kreppel and Zoller, 2018). As the development of odontogenic tumors was associated with remnants of the migrating epithelium at the cervical loop of the enamel organ, it was not surprising that the development of ameloblastoma was also linked to the enamel organ remnants of odontogenic epithelium and lining of odontogenic cyst. This odontogenic etiological origin was further supported by the similarities in the expression profiles of cytokeratin and vimentin between the developing tooth germ and ameloblastoma (Effiom, et al., 2018). The molecular pathogenesis of ameloblastoma is now attributed to dysregulation of the mitogen-activated protein kinase (MAPK) pathway based on studies using ameloblastoma tissues, cell lines, and transgenic mice (Brown, et al., 2015).

Various risk factors have been associated and studied which might be involved in triggering development and progression of ameloblastoma such as chronic inflammatory responses, viral infection (human papillomavirus), malnutrition, deficiency of either vitamins/proteins/minerals, improper dental health, individual's genetic polymorphism (Toprani, 2020), chemical exposure (arsenic, lead, drugs, occupational-related exposures), radiation, and pollution (air, water, and foodborne) (Sun, et al., 2020).

Interaction between ameloblastoma cells and bone marrow stromal cells (BMSCs) increased the secretion of interleukin (IL)-8 and activin A by BMSCs. Tumor-derived tumor necrosis factor (TNF)- $\alpha$ modulated the expression of IL- 8 in BMSCs. IL-8 could stimulate receptor activator of nuclear factor (NF)- $\mathrm{kB}$ (RANK) ligand (L) in contributing to osteoclast formation. In BMSCs culture, ameloblastoma cells stimulate the secretion of Activin A. The mechanism via cell-to-cellmediated activation of c-Jun $\mathrm{N}$-terminal kinase activation. Osteoclast formation and function were induced by Activin A as a cofactor of RANKL (Liu, et al., 2019). RANKL binding will trigger the activation of the osteoclast. Besides RANKL, the progression also involved matrix metalloproteinases (MMPs). MMP-1, MMP-2, and MMP-9 were released by ameloblastoma (Yoshimoto, et al., 2016). A study confirmed the bone-resorption mechanism of ameloblastoma by observing the role of RANK and MMP-9. On the other hand, osteoprotegerin was found to act as a bone resorption inhibitory factor (Qian and Huang, 2010).

\section{CLINICAL, RADIOGRAPHIC, AND HISTO- LOGICAL FEATURES OF AMELOBLASTOMA}

\section{Clinical Appearance}

In general unicystic, multicystic, dermoplastic, and plexiform ameloblastomas have the same clinical appearances, which are extra and intraoral swelling with the absence of pain (Figueiredo, et al., 2014; Kamboj, et al., 2015). The swelling was the most common symptom (38\%) (Kim and Jang, 2001). The reported initial chief complaint was the swelling of the lower jaw and/ or face, for a period ranging from 1 to 4 months, usually asymptomatic (Figueiredo, et al., 2014). Other rare symptoms experienced by ameloblastoma patients such as local discomfort (11.3\%), purulent discharge $(4.2 \%)$, pain and paresthesia $(1.4 \%)$, tooth mobility (1.4\%), swelling, and purulent discharge (2.8\%) (Kim and Jang, 2001). Sometimes the pain will occur due to hemorrhage in the adjacent soft tissue (Kreppel and Zoller, 2018).

Recurrences have been reported to occur between 2 and 5 years for more than $50 \%$ of the cases. The rest can occur sporadically 20,30 , and even 45 years later. Usually, recurrent lesions were smaller than the primary lesion, and thus, segmental resection may be more limited (Parmar, et al., 2016).

Maxillary ameloblastomas were not commonly found, and approximately about $15 \%$ of 
all ameloblastoma cases. Maxillary ameloblastomas are often be associated with an aggressive course. The surgery challenges are different on maxillary ameloblastoma compare to mandible ameloblastoma. Complication into adjacent spaces such as the maxillary antrum is often detected at later stages of maxillary ameloblastoma (Yang, et al., 2017). If orbital is involved in maxillary ameloblastoma, usually related to high mortality, morbidity, and recurrence. Only 23 well-documented cases and 3 publications in ophthalmic were reported. This indicated the maxillary ameloblastoma was extremely rare. The clinical presentation of recurrent maxillary ameloblastoma such as nasal discharge with blood, swelling, nasal obstruction, pushed-down hard palate, and eye proptosis (Qahtani, et al., 2019).

\section{Radiographic Feature}

Multilocular and unilocular ameloblastomas had the same radiographic features. Well-defined margin, corticated thick, adjacent root resorption may present or absent, buccal/ lingual/inferior border of mandible cortical expansion, and usually found at posterior or anterior of the mandible. Radiographic features of unilocular and multilocular ameloblastomas can be differentiated. The unilocular usually has a smooth shape of margin, absent of septae, and internal structure radiolucent (Figueiredo, et al., 2014). Meanwhile, the multilocular can appears with scalloped margin, thin curved or coarse curved septae, and mix or soap bubble internal radiolucent structure. Radiolucency cyst-like appearance referred to unicystic type ameloblastoma. However, unlike cyst, unicystic ameloblastoma may show trabeculae within the lumen and had a discontinuity in the peripheral cortex. Another radiolucency appearance to be seen is a large radiolucent area with scalloped borders, and it is referred to as one most common appearances of spider-web patterns. From the center of the lumen, coarse strands of trabeculae radiate peripherally, giving rise to a gross caricature of a spider. Multilo- cular radiolucency is seen as a soap bubble pattern. This pattern had a varying size, multi-chambered, or multicystic "bunch of grapes" appearance giving rise to the soap-bubble. The last pattern seen in radiolucency was honeycomb appearance, also known as solid or beehive pattern. The honeycomb appearance arose from multiple small radiolucencies that are seen surrounded by hexagonal or polygonal thick-walled bony cortices (More, et al., 2012).

\section{Histological Findings}

In the WHO classification for odontogenic tumors, types of ameloblastomas are solid/ multicystic, plexiform, and follicular. Other types of ameloblastomas are unicystic, extraosseousperipheral, and desmoplastic (Arora, 2015). Microscopic patterns of ameloblastomas can be uniform or mixed and divided into the follicular, plexiform, acanthomatous, spindle, basal cell-like, desmoplastic, and granular cell. The most common type was the solid or multicystic type with $91 \%$ prevalence of ameloblastoma followed by unicystic, extraosseous, and desmoplastic type with $6 \%$, $2 \%$, and $1 \%$, respectively. Benign ameloblastoma is a unicystic type and divided into intraluminal and intramural subtypes. On the other hand, if the invasion of supporting connective tissue was the intramural subtype. The appearance which is centered within the marrow space and encapsulated by bone was dermoplastic ameloblastoma. The peripheral ameloblastomas are extra-osseous and do not involve the underlying bone (McClary, et al., 2016).

The classical histological pattern of ameloblastoma described by Vickers and Gorlin is characterized by a peripheral layer of tall columnar cells with hyperchromasia, reversely polarized nuclei and sub-nuclear vacuole formation (Masthan, et al., 2015). Follicular type is composed of many small islands of the peripheral layer of cuboidal or columnar cells with a reversely polarized nucleus. The term plexiform refers to the appearance of anastomosing islands of odontogenic epithelium, 
with double rows of columnar cells in a back-toback arrangement. In acanthomatous type, the cells occupying the position of stellate reticulum undergo squamous metaplasia, with keratin pearl formation in the center of tumor islands. In granular cell ameloblastoma, the cytoplasm of stellate reticulum-like cells appears coarse granular and eosinophilic. Basal cell type, the epithelial tumor cells are less columnar and arranged in sheets. The desmoplastic variant is composed of the dense collagen stroma, which appears hypocellular and hyalinised (Rajendran, 2012).

A cyto-histological study investigated the ameloblastoma expression of B-cell lymphoma (Bcl)-2 related proteins. $\mathrm{Bl}-2$ and $\mathrm{Bcl}-\mathrm{x}$ were found more in the outer layer cells of the tumor island. On the other hand, Bcl-2-associated X-protein (Bax) and Bcl2-antagonist/killer (Bak) were found more in the inner layer. This finding indicating the outer layer cell had apoptotic inhibition. Meanwhile, the inner layer cell was experienced more apoptosis (Sandra, et al., 2001). Due to the active proliferating state, Proliferating Cell Nuclear Antigen (PCNA) and $\mathrm{Ki}-67$ of ameloblastoma were investigated. The cytological pattern of ameloblastoma showed PCNA and Ki-67 were expressed in the outer layer. Higher expression of PCNA and Ki-67 suggested the ameloblastoma had a higher proliferation activity in the outer layer (Sandra, et al., 2001).

\section{OSTEOCLASTIC MECHANISM AND ITS UN- DERLYING PATHWAYS IN AMELOBLAS- TOMA}

Bone resorption is a complex process initiated by the proliferation of immature osteoclasts. Osteoclastic differentiation is principally regulated by RANK/RANKL/OPG system. The interaction between RANK and RANKL plays a critical role in promoting osteoclast differentiation and activation, thus leading to bone resorption. RANKL binds to RANK on the surface of preosteoclasts and stimulates the development and activation of osteoclasts. OPG is a soluble decoy receptor for RANKL that blocks osteoclast formation by inhibiting RANKL binding to RANK. The enhanced RANKL expression or decreased OPG levels play an important role in tumor-associated bone destruction (Tekkesin, et al., 2011; Al-Rawi, et al., 2018).

The current concept of bone resorption caused by ameloblastoma occurs as a result of activities by peritumoral osteoclasts. It is believed activation of peritumoral osteoclasts by RANKL is released from the ameloblastoma (Yoshimoto, et al., 2016). RANKL-induced NF- $\kappa \mathrm{B}$ activation for osteoclast differentiation and function. Activated $\mathrm{T}$ cells produce the RANKL that directly controls bone remodeling and osteoclastogenesis. RANKL was expressed in all types of ameloblastomas, and it could be the regulating factor of bone metabolism (Tekkesin, et al., 2011; Sandra, et al., 2005).

Several cytokines such as IL-1, IL-6, IL-8, IL-11, and IL-17 were bone-resorbing factors and have been reported to trigger RANKL expression in BMSCs. Upregulating IL-8 and activin A triggered osteoclastogenesis from the interactions between ameloblastoma cells and BMSCs. Ameloblastoma-derived TNF- $\alpha$ will enhance the production of IL-8 in BMSCs, further induced osteoclast formation directly or by upregulating RANKL expression in BMSCs. The activation of the JNK pathway in the presence of ameloblastoma cells induced stimulation of Activin A secretion in BMSCs. Osteoclast formation and function stimulated by RANKL and activin A acted as a co-factor of RANKL. Overexpression of IL-8 not only correlates with tumor growth, angiogenesis, and metastasis but also serves a critical role in osteoclast formation. Multiple signals, including IL- $1 \alpha$, IL- $1 \beta$, and TNF- $\alpha$, are correlated with the production of IL-8. A study suggested RANKL expression through IL-8-dependent pathway from the interaction between the ameloblastoma cells and BMSCs (Fuchigami, et al., 2014; Liu, et al., 2019). (Figure 1)

Expressions of IL-1 $\alpha$ and IL-6 contribute to the tumor size of ameloblastoma. IL-1 $\alpha$ and IL-6 are known to be the major 
cytokines for osteolysis. Based on the result, the author suggested IL- $1 \alpha$ and IL- 6 mediating bone lysis play a vital role in ameloblastoma expansion in the jawbone (Senguyen, et al., 2011).

Besides RANKL, osteoclastogenesis stimulation by TNF- $\alpha$ has been confirmed. Tartrate-resistant acid phosphatase-positive multinucleated cells formation directly induced by TNF- $\alpha$. This mechanism will produce resorption pits on the bone (Sandra, et al., 2005; Feng, et al., 2019). Besides, matrix metalloproteinases (MMPs) and Cathepsin $\mathrm{K}$ are involved in the degradation of the organic matrix in bone, mainly type I collagen (Qian, et al., 2010).

Regulation of IL-6 and MMP-9 can be modulated by TNF- $\alpha$ in ameloblastoma cells, which implicated the ameloblastoma pathological behavior, such as bone resorption. TNF- $\alpha$ secreted from the tumor directly modulates osteoclasts and may also act on osteoclastogenesis by introducing IL-6 and MMP-9 via autocrine mechanisms in ameloblastoma. TGF- $\beta$ and interferon- $\gamma$ (IFN- $\gamma$ ) have also been reported to be essential regulators of osteoclastogenesis. TGF- $\beta$ is an essential element, as it functions as a cofactor of RANKL. IFN- $\gamma$ has also been shown to induce activation and secretion of the osteoclastogenesis factors. TGF- $\beta$ and IFN- $\gamma$ could increase the levels of TNF- $\alpha$-induced IL-6 and MMP-9. TGF- $\beta$ and IFN- $\gamma$ cooperate to regulate TNF- $\alpha$ mediation of genes related to bone resorption in ameloblastoma cells and may influence ameloblastoma tumor growth and invasiveness. TNF- $\alpha$ was shown to increase NF- $\kappa B$ activation via inhibitor of $\kappa \mathrm{B}(\mathrm{I} \kappa \mathrm{B}) \alpha$ phosphorylation to induce IL-6 and MMP-9, while the NF- $\mathrm{KB}$ inhibitor dramatically decreased TNF- $\alpha$-mediated IL-6 and MMP-9 expressions. A study revealed that TNF- $\alpha$-induced NF- $\kappa B$ signaling plays a vital role in pathological behavior, such as bone resorption in ameloblastoma cases. On the opposite, NF- $\mathrm{KB}$ inhibitor blocked TNF- $\alpha$-mediated synergistic induction of MMP-9 and IL- 6 in the presence of IFN- $\gamma$ or TGF- $\beta$. Thus, for NF- $\kappa$ B activation, TNF- $\alpha$ is initially triggered, followed by other signal pathways stimulated by IFN- $\gamma$ or TGF- $\beta$ cross-talk (Ohta, et al., 2017). (Figure 1)

MMPs may contribute to ameloblastoma behavior, which can transduce the Extracellular Related Kinase (ERK) 1/2 pathway. In ameloblastoma, MMPs mediate bone resorption. The tissue inhibitors of metalloproteinases (TIMPs), Transforming Growth Factor (TGF)- $\alpha$, and Epidermal Growth Factor (EGF) cooperate to regulate ameloblastoma proliferation. Distinct signaling pathways have been implicated in TIMP growth-promoting activity, including ERK 1/2. ERK 1/2 signals are generated by growth factors and tissue inhibitors of MMPs (Siqueira, et al., 2010). Besides MMPs, The TN$\mathrm{F}-\alpha$ induction for ameloblastoma was transduced by Phosphoinositide 3-Kinases (PI3K), Akt, and Mitogen-activated Protein Kinase (MAPK). This induction will impact ameloblastoma proliferation activity and survival (Hendarmin, et al., 2005).

RANKL and MMP-9 were found to be immunohistochemically expressed in ameloblastoma. MMP-9 (gelatinase B, a $92 \mathrm{kDa}$ type IV collagenases) is involved in the process of tumor invasion by mediating degradation of basement membrane and remodelling of extracellular matrix (ECM), and one of the most important proteinases involved in bone resorption. MMP-9 is not only contributed to bone matrix degradation but also as a regulator in the initial bone resorption process. MMP-9 presents in ameloblastoma to digest bone matrix and release mitogens, which could increase tumor proliferation (Qian, et al., 2010; Anne, et al., 2014; Pinheiro, et al., 2004).

MMPs and RANKL play important roles in cell proliferation, invasion, and bone resorption. Wnt/ $\beta$-catenin signaling, which is involved in the progression of ameloblastoma, can regulate MMP and RANKL expression. $\beta$-catenin is a key factor in the Wnt signaling pathway, acting as a transcriptional activator. Activation of the Wnt/ $\beta$ catenin pathway inhibits glycogen synthase kinase-3 $\beta$ (GSK-3 $\beta$ ) enzymatic activity within the destruction complex by phosphorylating GSK$3 \beta$ (Yang, et al., 2018). Wnt/ $\beta$-catenin signaling, 
through GSK-3 $\beta$ inactivation, can also affect osteoclast differentiation. Several mechanisms related to $\beta$-catenin signaling are suggested to modulate RANK-RANKL-OPG signaling in osteoclasts (Amirhosseini, et al., 2018). (Figure 1)

Osteoclast differentiation is completed by the expression of a large number of related marker genes, such as MMP-9, Nuclear Factor of Activated
T Cells 1 (NFATc1), TRAP, C-Src, and cathep$\sin \mathrm{K}$. Most of which are target genes of NFATc1. NFATc1 is a well-known master regulator of osteoclastogenesis and function (Sandra, et al., 2005). This osteoclastogenesis provides the space for the ameloblastoma to expand in the bone (Gomes, et al., 2010).

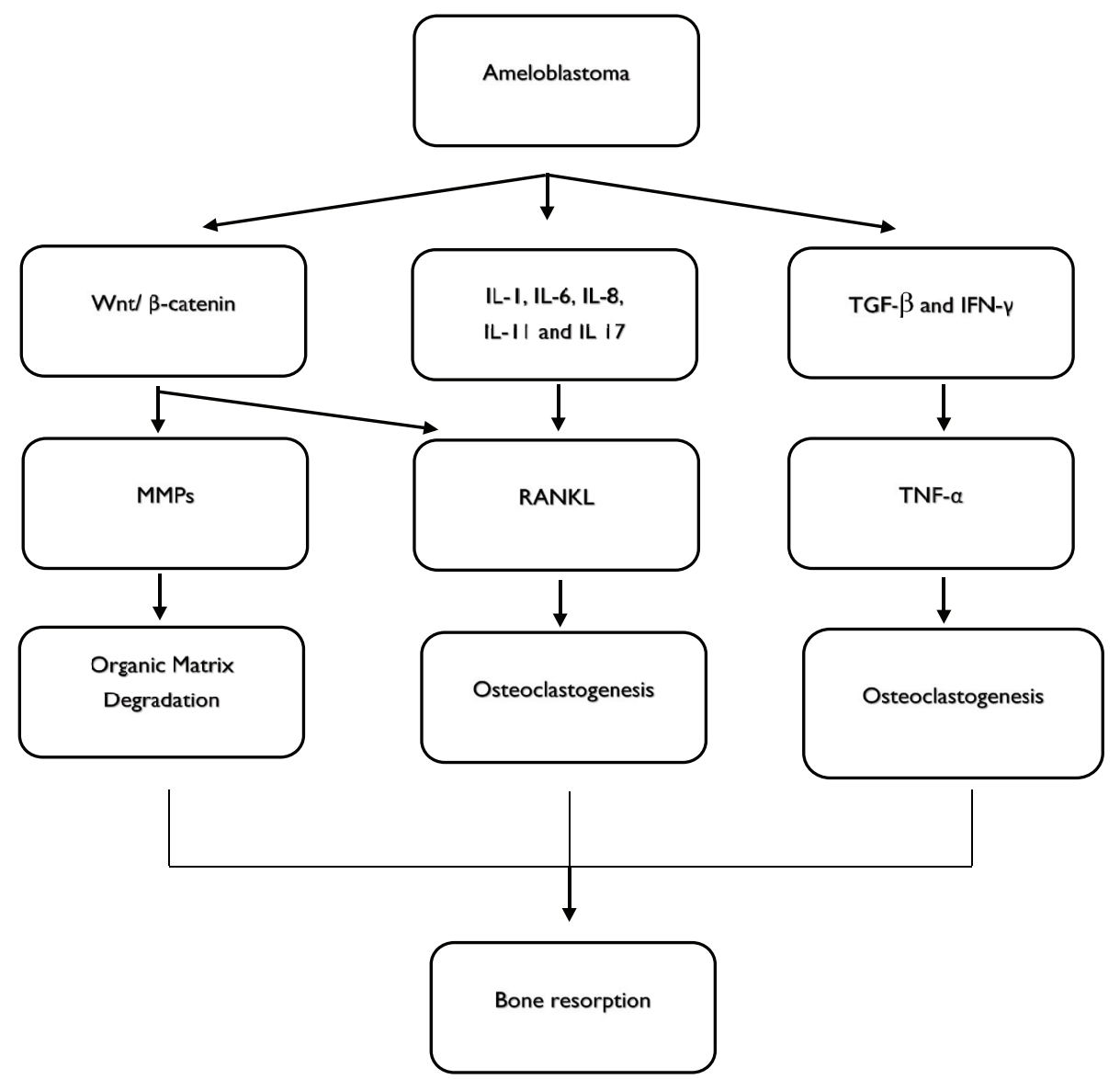

Figure 1. Bone resorption mechanism of ameloblastoma.

\section{MANAGEMENT OF AMELOBLASTOMA AND RECURRENT PREVENTION}

Lesion elimination should always be the main focus for the best treatment choice. The treatment method will influence on the life and rehabilitation of the patients. Treatment options ranging from conservative to radical bone resections (Maia and Sandrini, 2017).
MMP-2 and MMP-9 are proteolytic enzymes and target genes of Wnt pathways. Both MMPs mediate tumor growth and invasion by regulating events like neoangiogenesis, antiapoptosis, invasion, and metastasis. The elevated neovascularization or angiogenesis indicated the tumor prone to recurrence. Each type of ameloblastoma had the variant expression of the MMPs. High expression of MMPs was reported to be correlated 
with the high proliferative ameloblastoma with elevated neoangiogenesis. Therefore, adequate treatment with more extensive resection should be considered. In contrast, lower expression of these markers suggests the treatment could be done with the conservative procedure (Kibe, et al., 2013; Sah, et al., 2013). (Figure 2)

MMPs role of action is mainly the degradation of ECM. While RANKL is involved in the mechanism of how the tumor expands in the bone, RANKL is required for osteoclast development. Therefore, target therapy on these markers could be potential (Al-Rawi, et al., 2018). Invasion by ameloblastoma cells expressing RANKL, marked by a larger tumor volume, needs more invasive procedures, such as segmental resection with the discontinuity of the bone piece, even removing the periosteum, and overlying soft tissue (Dissanayake et al., 2011). (Figure 2)

Conservative methods such as enucleation and curettage require less operation time, but these methods are assumed to be associated with high recurrence rates and re-resection (Hendra, et al., 2019). Recurrence rates of solid and unicystic ameloblastomas revealed a lower risk of recurrence after radicalization compared to conservative treatment (Antonoglou and Sandor, 2015). Recurrence rates were 3\% for radical treatment and $21 \%$ for conservative treatment. The solid or multicystic ameloblastoma may behave more aggressively than the unicystic ameloblastoma based on the recurrence rates (Hendra, et al., 2019). Despite the surgery, another important aspect is the awareness of the patients since they will

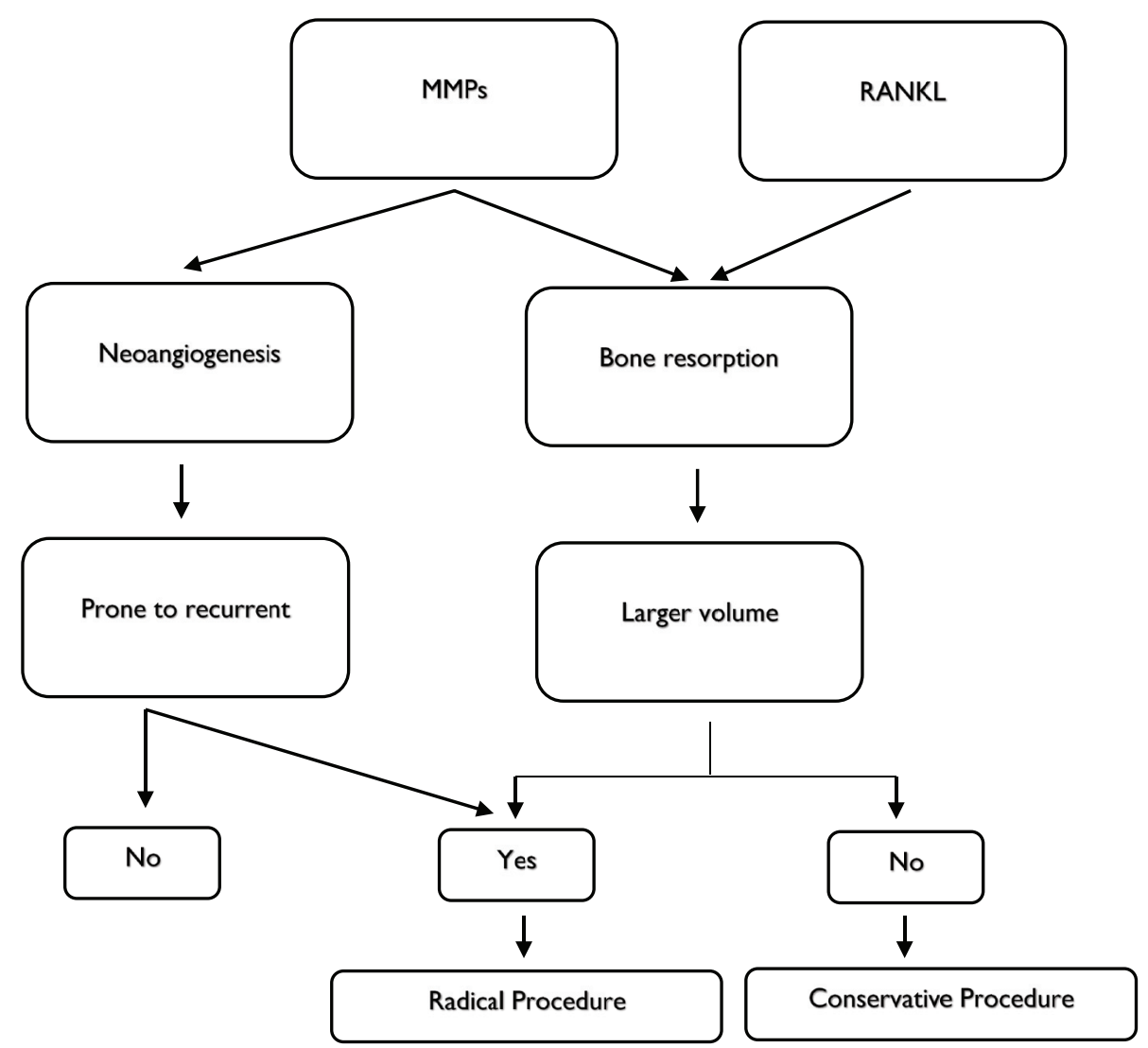

Figure 2. Procedure selection for ameloblastoma based on bone expansion and recurrent prevention. 
need more rigorous attention and care regarding their oral health, including specific diet, follow-up, and periodical examinations. (França, et al., 2012).

\section{CONCLUSION}

Bone resorption in ameloblastoma occurs as a result of peritumoral osteoclasts activities. Osteoclastic induction of ameloblastoma cells is associated with RANKL, TNF- $\alpha$, and MMPs. RANKL expression will induce osteoclast differentiation and function. TNF- $\alpha$ induces osteoclast formation and modulates the regulation of MMPs. While MMPs, despite mediating degradation of the basement membrane, also play a role in and neovascularization event. By understanding the osteoclastogenesis in ameloblastoma cases, together with surgery and other target therapies, the RANKL, TNF- $\alpha$, and MMPs should be targeted so that the growth and recurrence of ameloblastoma can be managed.

\section{REFERENCES}

Al-Rawi, N.H., Al-Siraj, A.K. and Majeed, A.H., 2018, Comparison of osteoclastogenesis and local invasiveness of ameloblastoma keratocystic odontogenic tumor, Eur. J. Dent., 12(1), 36-42.

Amirhosseini, M., Madsen, R.V., Escott, K.J., Bostrom, M.P., Ross, F.P. and Fahlgren, A., 2018, GSK-3B Inhibition Suppresses Instability-induced Osteolysis by a Dual Action on Osteoblast and Osteoclast Differentiation, J. Cell. Physiol., 233(3), 2398-2408.

Anne, R., Krisnuhoni, E., Chotimah, C. and Latief, B.S., 2014, Matrix metalloproteinase-9 (MMP-9) expression in different subtypes of ameloblastoma, J. Maxillofac. Oral. Surg., 13(3), 281285.

Antonoglou, G.N. and Sandor, G.K., 2015, Recurrence rates of intraosseous ameloblastomas of the jaws: A systematic review of conservative versus aggressive treatment approaches and metaanalysis of non-randomized studies, Journal of
Cranio-Maxillo-Facial Surgery, 43(1), 149-157.

Arora, S., 2015, Unicystic ameloblastoma: A perception for the cautious interpretation of radiographic and histologic findings, J. Coll. Physician. Surg. Park., 25(10), 761-764.

Brown, N.A., Betz, B.L., Weigelin, H.C., ElenitobaJohnson, K.S., Lim, M.S. and Bailey, N.G., 2015, Evaluation of allele-specific PCR and immunohistochemistry for the detection of BRAF V600E mutations in hairy cell leukemia, Am. J. Clin. Pathol., 143(1), 89-99.

Dissanayake, R.K., Jayasooriya, P.R., Siriwardena, D.J. and Tilakaratne W.M., 2011, Review of metastasizing (malignant) ameloblastoma (METAM): pattern of metastasis and treatment, Oral. Surg. Oral. Med. Oral. Pathol. Oral. Radiol. Endod., 111(6), 734-41.

Effiom, O.A., Ogundana, O.M., Akinshipo, A.O. and Akintoye, S.O., 2018, Ameloblastoma: current etiopathological concepts and management, Oral. Diseases., 24(3), 307-316.

Feng, W., Guo, J. and Li, M., 2019, RANKL-independent modulation of osteoclastogenesis, J. Oral. Biosci, 61(1), 16-21.

Figueiredo, N.R., Dinkar, A.D., Meena, M., Sujata, S. and Manisha, K., 2014, Ameloblastoma: A clinicoradiographic and histopathologic correlation of 11 cases seen in Goa during 2008-2012, Contemp. Clin. Dent., 5(2), 16-165.

França, L.J., Curioni, O.A., Paiva, D.L., Vianna, D.M., Dedivitis, R.A. and Rapoport, A., 2012, Ameloblastoma demographic, clinical, and treatment study: analysis of 40 cases, Braz. J. Otorhinolaryngol., 78(3), 38-41.

Fuchigami, T., Kibe, T., Koyama, H., Kishida, S., lijima, M., Nishizawa, Y., et al., 2014, Regulation of IL-6 and IL-8 production by reciprocal cell-to-cell interactions between tumor cells and stromal fibroblasts through IL-1a in ameloblastoma, Biochem. Biophys. Res. Commun., 451, 491-496.

Gomes, C.C., Duarte, A.P., Diniz, M.G. and Gomez, R.S., 2010, Current concepts of ameloblastoma 
pathogenesis, J. Oral. Pathol. Med., 39, 585591.

Hendra, F.N., Natsir-Kalla, D.S., Van-Cann, E.M., de-Vet, H., Helder, M.N. and Forouzanfar, T., 2019, Radical vs. conservative treatment of intraosseous ameloblastoma: Systematic review and meta-analysis, Oral. Diseases., 25(7), 1683-1696.

Hendarmin, L., Sandra, F., Nakao, Y., Ohishi, M. and Nakamura, N., 2005, TNFalpha played a role in the induction of Akt and MAPK signals in ameloblastoma, Oral. Oncol., 41(4), 375-82.

Intapa, C., 2017, Analysis of Prevalence and Clinical Features of Ameloblastoma and its Histopathological Subtypes in Southeast Myanmar and Lower Northern Thailand Populations: A 13-Year Retrospective Study, J. Clin. Diagn. Res., 11(1), ZC102-ZC106.

Kamboj, M., Shreedhar, B. and Chaturvedi, M., 2015, Plexiform unicystic ameloblastoma: A case report and data analysis in the Indian population, J. Maxillofac. Oral. Surg., 14(1), 407-411.

Kibe, T., Fuchigami, T., Kishida, M., lijima, M., Ishihata, K., Hijioka, H., et al., 2013, A novel ameloblastoma cell line (AM-3) secretes MMP9 in response to Wnt-3a and induces osteoclastogenesis, Oral. Surg. Oral. Med. Oral. Pathol. Oral. Radiol., 115(6), 780-788.

Kim, S. and Jang, H., 2001, Ameloblastoma: A clinical, radiographic, and histopathologic analysis of 71 cases, Oral. Surg. Oral. Med. Oral. Pathol. Oral. Radiol. Endod., 91, 649-653.

Kreppel, M. and Zoller, J., 2018, Ameloblastomaclinical, radiological, and therapeutic findings, Oral. Dis., 24(1-2), 63-66.

Liu, X., Chen, Z., Lan, T., Liang, P. and Tao, Q., 2019, Upregulation of interleukin-8 and activin A induces osteoclastogenesis in ameloblastoma, Int. J. Mol. Med., 43(6), 2329-2340.

Maia, E.C. and Sandrini, F.A.L., 2017, Management techniques of ameloblastoma: a literature review, RGO. Rev. Gaúch. Odontol., 65(1), 62-69. Masthan, K., Anitha, N., Krupaa, J., Manikkam, S.,
2015, Ameloblastoma, J. Pharm. Bioall. Sci., 7, 167-70.

McClary, A.C., West, R.B., McClary, A.C., Pollack, J.R., Fischbein, N.J., Holsinger, C.F., et al., 2016, ameloblastoma: a clinical review and trends in management, Eur. Arch. Otorhinolaryngol., 273(7), 1649-1661.

More, C., Tailor, M., Patel, H.J., Asrani, M., Thakkar, K. and Adalja, C., 2012, Radiographic analysis of ameloblastoma: a retrospective study, Indian. J. Dent. Res., 23(5), 698.

Ohta, K., Naruse, T., Ishida, Y., Shigeishi, H., Nakagawa, T., Fukui, A., et al., 2017, TNF-a-induced IL-6 and MMP-9 expression in immortalized ameloblastoma cell line established by hTERT, Oral. Dis., 23(2), 199209.

Parmar, S., Al-Qamachi, L. and Aga, H., 2016, Ameloblastomas of the mandible and maxilla, Curr. Opin. Otolaryngol. Head. Neck. Surg., 24, 148-154.

Petrovic, I.D., Migliacci, J., Ganly, I., Patel, S., Xu, B. and Ghossein, R., et al., 2018, Ameloblastomas of the mandible and maxilla, Ear. Nose. Throat. J., 97(7), E26-E32.

Pinheiro, J.J.V., Freitas, V.M., Moretti, A.I.S., Jorge, A.G., Jaeger, R.G., 2004, Local invasiveness of ameloblastoma. Role played by matrix metalloproteinases and proliferative activity, Histopathology., 45, 65-72.

Qahtani, K.A.L., Alkhudhayri, A.F., Islam, T., Mufargi, K.A.L., Shakweer, W.A.L. and Otaibi, F., 2019, Recurrent unicystic maxillary ameloblastoma presenting as unilateral proptosis, Saudi. J. Ophthalmol., 33(1), 94-98.

Qian, Y. and Huang, H.Z., 2010, The role of RANKL and MMP-9 in the bone resorption caused by ameloblastoma, J. Oral. Pathol. Med., 39(8), 592-598.

Rajendran, R., 2012, cyst and tumors of odontogenic origin. In: Rajendran R, Sivapathasundharam B, ed., 2012, Shafer's Text Book of Oral Pathology, $7^{\text {th }}$ ed. Indian: Elsevier. pp. 259-313. 
Ruslin, M., Hendra, F.N., Vojdani, A., Hardjosantoso, D., Gazali, M., Tajrin, A., et al., 2018, The Epidemiology, treatment, and complication of ameloblastoma in East-Indonesia: 6 years retrospective study, Med. Oral. Patol. Oral. Cir. Bucal., 23(1), e54-e58.

Saghravanian, N., Salehinejad, J., Ghazi, N., Shirdel, M. and Razi, M., 2016, A 40-year Retrospective Clinicopathological Study of Ameloblastoma in Iran, Asian. Pac. J. Cancer. Prev., 17(2), 619623.

Sah, P., Menon, A., Kamath, A., Chandrashekar, C., Carnelio, S. and Radhakrishnan, R., 2013, Role of immunomarkers in the clinicopathological analysis of unicystic ameloblastoma, Dis. Markers., 35(5), 481-488.

Sandra, F., Hendarmin, L., Kukita, T., Nakao, Y., Nakamura, N. and Nakamura, S., 2005, Ameloblastoma induces osteoclastogenesis: a possible role of ameloblastoma in expanding in the bone, Oral. Oncol., 41(6), 637-644.

Sandra, F., Nakamura, N., Mitsuyasu, T., Shiratsuchi, Y. and Ohishi, M., 2001, Two relatively distinct patterns of ameloblastoma: an anti-apoptotic proliferating site in the outer layer (periphery) and a pro-apoptotic differentiating site in the inner layer (center), Histopathology., 39(1), 93-98.

Sandra, F., Mitsuyasu, T., Nakamura, N., Shiratsuchi, Y. and Ohishi, M., 2001, Immunohistochemical evaluation of PCNA and Ki-67 in ameloblastoma, Oral. Oncol., 37(2),193-8.

Senguyen, B. and Oygur, T., 2011, Investigation of interleukin-1 alpha and interleukin-6 expression and interleukin-1 alpha gene polymorphism in keratocystic odontogenic tumor and ameloblastomas, Med. Oral. Patol. Oral. Cir. Bucal., 16(4), 467-72.
Singh, T., Wiesenfeld, D., Clement, J., Chandu, A. and Nastri, A., 2015, Ameloblastoma: demographic data and treatment outcomes from Melbourne, Australia, Aust. Dent. J., 60(1), 24-29.

Siqueira, A.S., Carvalho, M.R.D., Monteiro, A.C.D., Freitas, V.M., Jaeger, R.G. and Pinheiro, J.J.V., 2010, Matrix metalloproteinases, TIMPs and growth factors regulating ameloblastoma behavior, Histopathology., 57(1), 128-37.

Sun, T., Yang, W., Toprani, S. M., Guo, W., He, L., Deleo, A.B., et al., 2020, Correction to Induction of immunogenic cell death in radiation-resistant breast cancer stem cells by repurposing anti-alcoholism drug disulfiram, Cell. Commun. Signal., 18(1), 53.

Tekkesin, M.S., Mutlu, S. and Olgac, V., 2011, The role of RANK/RANKL/OPG signaling pathways in osteoclastogenesis in odontogenic keratocysts, radicular cysts, and ameloblastomas, Head. Neck. Pathol., 5(3), 248-253.

Toprani, S.M., 2020, DNA damage and repair scenario in ameloblastoma, Oral. Oncol., 108, 104804.

Yang, R., Liu, Z., Peng, C., Cao, W. and Ji, T., 2017, Maxillary ameloblastoma: Factors associated with risk of recurrence, Head. \& Neck., 39(5), 996-1000.

Yang, Z., Li, K., Liang, Q., Zheng, G., Zhang, S., Lao, X., et al., 2018, Elevated hydrostatic pressure promotes ameloblastoma cell invasion through upregulation of MMP-2 and MMP-9 expression via Wnt/B-catenin signaling, J. Oral. Pathol. Med., 47(9), 836-846.

Yoshimoto, S., Morita, H., Matsubara, R., Mitsuyasu, T., Imai, Y., Kajioka, S., et al., 2016, Surface vacuolar ATPase in ameloblastoma contributes to tumor invasion of the jaw bone, Int. J. Oncol., 48(3), 1258-1270. 